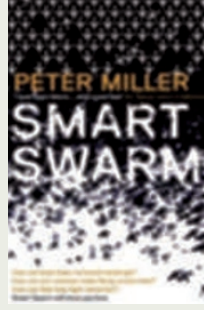

In Smart Swarm (Collins, 2010), journalist Peter Miller explains how the collective intelligence of swarms, shoals and flocks can be applied to solve practical problems. Ant colonies inspire factory production lines, telephone networks and transport routes; termites offer clues to climate control; and fish shoals suggest ways in which military robots might patrol and interact.

Miller explains how understanding the intricacies of group behaviour can help us build improved systems and make better decisions.

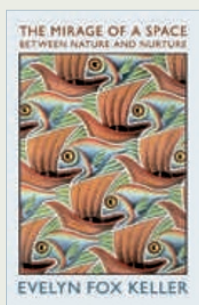

Nature and nurture are often described as unrelated opposites. In her critique The Mirage of a Space Between Nature and Nurture

(Duke Univ. Press, 2010), philosopherhistorian Evelyn Fox Keller asks why we separate the two. She shows that the divisive concept arose in the late nineteenth century, based on a tangle of ambiguous definitions of terms such as nature, nurture, gene and environment. Fox Keller suggests that the contemporary vocabulary of genetics can put an end to debates about nature versus nurture.

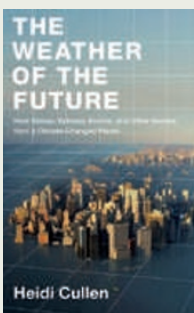

Climatologist Heidi Cullen describes how our weather will change if we do not curb carbon dioxide emissions. In The Weather of the

Future (HarperCollins, 2010), she draws on the latest climate models and interviews with experts to paint pictures of the local impacts of global warming. Focusing on seven locations around the world, from New York to Bangladesh, Cullen highlights the range of risks that threaten us, including sea-level rise, flooding and drought. She also sketches the possible weather patterns for US cities in 2050.

\title{
A smart vision of brain hacking
}

\author{
Inception \\ Directed by Christopher Nolan \\ Warner Bros Pictures: 2010 \\ On general release.
}

Inception is a visionary science-fiction film that does for dreaming what The Matrix did for virtual reality in 1999. It is directed by Christopher Nolan, who brought us Memento (2000), one of the best cinematic depictions of how it is to live with severe amnesia, and Batman Begins (2005).

Central to the film is a fictional technology that combines a powerful sedative with electronic gadgetry to enable one dreamer to enter the dream of another and manipulate its content. Dom Cobb (Leonardo DiCaprio) is a mind hacker, a specialist hired by corporations to extract secrets illegally from the minds of his targets. He also has a past that haunts him. Cobb is given the arduous task of inception - to covertly plant an idea in the subconscious of Robert Fischer, the heir to an industrial fortune, played by Cillian Murphy.

The film's premise is that ideas are unstoppable once they have taken seed, and can affect the world more than physical objects do.

For example, the idea of communism shaped history in the twentieth century, and the concept of a code drove Francis Crick to look for a way in which proteins could be encoded by DNA.

To carry out the job, Cobb assembles a team, including architecture student Ariadne, played by Ellen Page. During their preparation, the first of the film's breathtaking visuals occur: while dreaming, Ariadne bends and folds the streets of Paris, in a look that is a stunning homage to the artist M. C. Escher.

The characters inhabit nested dream worlds, falling asleep in one to enter the next manipulating a dream inside a dream inside a dream, and so on. At the final level is the unconscious psyche of Cobb. It is the majestic, crumbling dominion of Cobb's construct of his loving yet vengeful deceased wife Mal (Marion Cotillard), a creature of Freudian aggression, guilt and regret.

Intelligent scripting makes Inception vastly more engaging than a run-of-the-mill heist story. The film appeals to me, as a scholar seeking to understand how the physical brain is linked to the ineffable conscious mind, and as a neuroengineer designing interfaces to read out a person's innermost thoughts, because it suggests that the mind might be both read out and written into - two-way brain hacking.

The film also accurately reflects the phenomenology of dreams: physical laws can be ignored, such as when gravity is suspended after the team enters Fischer's dream; time moves faster than in reality; intense emotion can be felt; memory of dream events is absent; and external stimuli can be incorporated into the dream narrative before awakening.

Neuroscientists are beginning to link these

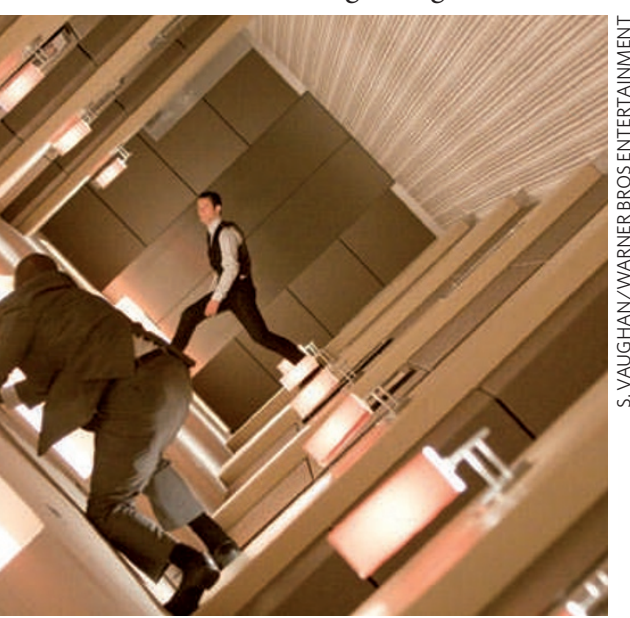

qualities of dreams to the underlying neurophysiology, through whole-brain imaging and electrode recording of neural activity in patients with epilepsy. However, in real life, all but the rare lucid dream lacks the feeling of voluntary action, or agency or control. This absence perhaps reflects the partial suppression of regions of the parietal cortex, a brain region that has been linked to the feeling of willing an action, during rapid-eye-movement sleep.

Inception is a game changer: a smart, megabudget Hollywood product that does not pander to its audience. Even weeks later, it leaves me with the queasy feeling that perhaps we too are merely dreaming. As the psychologist Havelock Ellis said, "Dreams are real as long as they last. Can we say more of life?"

Christof Koch is a professor of cognitive and behavioural biology at the California Institute of Technology, Pasadena 91125, USA, and at Korea University, Seoul 136-713, Korea. e-mail:koch@klab.caltech.edu 